\title{
As Práticas Parentais Positivas e Negativas como fatores colaborativos no
} rendimento escolar

\section{Positive and Negative Parenting Practices as collaborative factors in school performance}

\author{
Greicy Oliveira Nascimento*, Fabiana Soares Fernandes* \\ * Universidade Federal do Amazonas
}

\begin{abstract}
Resumo
As Práticas Educativas adotadas pelos pais (positivas e/ou negativas), apresentam grande relevância em todo o ambiente que a criança esteja inserida, principalmente o escolar. Diante disto, esta pesquisa teve como finalidade investigar se as práticas parentais exercem influência no desempenho escolar de 78 crianças que frequentavam o ensino fundamental. A análise dos dados demonstrou que a Prática adotada apresenta sim influencia no rendimento escolar das crianças investigadas. Foi possível perceber de que forma cada prática pode implicar no rendimento escolar das crianças. Ressaltamos a importância do uso de práticas positivas e a evitação do uso de práticas negativas.

Palabras clave: família, práticas parentais, rendimento escolar
\end{abstract}

\begin{abstract}
The educational parents practices (positive or negative), present great relevance in all the environment that the child is inserted, especially the school. In view of this, this research aimed to investigate whether parental practices exert an influence on the school performance of 78 children who attended elementary school. Data analysis showed that the adopted practice has a positive influence on the school performance of the children investigated. It was possible to see how each practice can imply in children's school performance. We emphasize the importance of using positive practices and avoiding the use of negative practices.
\end{abstract}

Keyword: family,parents practice, school performance

\section{Introdução}

A família como agente socializador primário tem um papel fundamental no desenvolvimento psicossocial de seus filhos, e a maneira como se dão as relações no ambiente familiar irão repercutir no desenvolvimento cognitivo, orgânico, ético e moral dos seus membros, durante todo o ciclo vital; É importante relevar que o contexto familiar tem sido identificado como a rede de apoio mais próxima, durante a infância, e um importante fator protetivo, pois a presença de características na família como afeto, intimidade e comunicação, podem ajudar as crianças a manterem um senso de estabilidade e rotina frente a mudanças e situações estressantes a que estão expostas no decorrer do seu cotidiano.

Considerando que a família é o primeiro e principal veículo de transmissão de valores, cultura, condutas, e um dos meios colaborativos para a formação da personalidade de cada indivíduo, este estudo relata as possíveis consequencias das práticas parentais recebidas em casa sejam elas, positivas ou negativas, mas que podem estar intimamente ligadas aos outros contextos sociais em que a criança está inserida como por exemplo, a escola. O estudo das práticas parentais vem sendo realizado por meio de escalas que verificam o clima emocional em que se expressam as interações pais-filhos e ainda tem como base, a influência dos pais em aspectos comportamentais, emocionais e intelectuais dos filhos.

O rendimento escolar, especificamente o desempenho escolar insatisfatório, o conhecido fracasso escolar, é uma temática recorrente na literatura científica, problema para o qual até o momento não foi encontrada uma solução. De acordo com Rosek e Serra (2015, p.168), são muitos os fatores que podem estar relacionados com o fracasso escolar, "os aspectos orgânicos, cognitivos, emocionais/afetivos, sociais e pedagógicos necessitam ser cuidadosamente observados e significados para que possamos compreender e intervir na problemática do sujeito em diferentes contextos (...)".

Outro aspecto que exerce grande influência no rendimento escolar de crianças são as práticas parentais adotadas no seio familiar (por seus pais ou cuidadores). Cada prática parental possui uma consequência, principalmente no que se refere ao processo de ensino e aprendizagem dos filhos. A partir de então a classificação dos comportamentos educativos adotados pelos pais justifica-se por ser uma teoria ainda pouco explorada no contexto brasileiro, especialmente na região Amazônica, na qual não se localizam estudos nessa área, além de ser um modelo que vem sendo 
utilizado em diversas investigações relacionadas às famílias, apresentando excelentes resultados.

\section{A família como principal agente socializador e desenvolvimentista do indivíduo.}

O sentimento de família tal qual é conhecido atualmente, surgiu no fim do século XVII e início do século XVIII, devido a uma mudança na organização familiar. Anteriormente a este período os casamentos eram realizados por contratos e não possuíam qualquer ligação com o carinho, amor e afeto, a família se concretizava apenas num conjunto de sustentação material, sem laços afetivos. Com o passar dos anos, o termo família passou a ganhar credibilidade afetiva, as crianças passaram a ter um outro papel diferente do qual se ocupava na Idade Média, passaram a ser vistas como seres humanos que necessitavam de cuidados, tanto material quanto afetivo.

As mudanças nas relações matrimoniais, abrem espaço para um novo olhar sobre a criança, que antes disto era vista como um ser que não precisava de atenção e que possuía a capacidade de se virar sozinha, sem qualquer auxílio dos pais. Este ideário foi se transformando ao longo dos anos, e assim como as relações entre homem e mulher se transformaram, a relação pais e filhos também passaram por novas ramificações e mudanças. Os pais passam a ser os principais responsáveis pela criação e proteção da criança, dotados para a promoção da educação e de incumbir os valores ditos relevantes para a sociedade (NERY, 2012). Assim, constrói-se o modelo "ideal" de família dos dias de hoje, assumindo sua função moral e espiritual, carregando um novo papel de socialização do indivíduo, sendo capaz de transmitir valores, crenças, ideias e significações, moldando e transformado o ser humano de acordo com seus ideários.

Silva (2009) destaca a família como principal agente de socialização à medida que esta instituição social é capaz de reproduzir padrões culturais sobre o indivíduo. A transmissão cultural também carrega um aparato geral de regras que predominam naquele determinado grupo social que a agora a criança também faz parte. Nessa mesma perspectiva Nery (2012) propaga a ideia de que as condutas dos pais podem colaborar para profundos traumas emocionais que se estenderão ao longo do ciclo vital para a criança, e que devido a isto a família passou a ter grande preocupação em relação à educação dos filhos. Assim, o relacionamento entre pais e filhos ganhou mais autenticidade e menos autoritarismo.

Nos dias atuais se origina um novo contexto social no qual a família está inserida, uma era globalizada, tecnológica e computadorizada, dando origen a um olhar pós-moderno para essa instituição social, que passa a ser vista por alguns autores como um veículo de transmissão de valores sociais que está se desestruturando e deteriorando, não conseguindo mais manter determinadas tradições e nem gerir suas relações, perdendo o controle sobre seus membros, colaborando para uma estrutura familiar com dificuldades para lidar com as mudanças contemporâneas (SILVA, 2009). No decorrer das mudanças na sociedade surgiram muitas discussões, levantando a conjectura de que a família está em processo de desagregação ou de enfraquecimento, e até mesmo há quem acredite no seu desaparecimento.

Silva (2009) continua explicando como ocorre o desequilíbrio da constituição familiar ao salientar que, talvez pelo fato de os pais não conseguirem equilibrar amor e limites e apreensivos com a possibilidade de traumatizar os filhos, deixaram de estabelecer expectativas firmes para que os mesmos amadurecessem e se tornassem independentes. Ao se depararem com novos modos de viver e de se relacionar os pais tornam-se indecisos, passam a questionar, a relativizar, a mudar ou a ficar sem parâmetros sobre como agir com suas crianças. A autora faz uma comparação, citando a importância de se manter o equilíbrio na educação dos filhos por meio de uma analogia da educação dos mesmos com a "poda" das plantas, especificamente das roseiras. Esclarece que esta poda deve ser feita de maneira adequada e que é assim que os adultos deveriam fazer com as crianças: colocar limites no momento certo, de forma adequada para garantir a sobrevivência e o fortalecimento da criança.

Diante deste contexto, no qual predomina o amor, os limites parecem ser coisas do passado, da era do tradicionalismo. Os pais passaram a acreditar que seu papel básico era dar amor, isto é traduzido por satisfazer as vontades dos filhos. Essas transformações confundiram os pais, não os deixando perceber que os limites fazem parte do cuidado, que faz parte do amor; portanto, não dar limites, implica não estar atento, não cuidar, o que se traduz por descuido, descaso, desamor. O esperado é que a família seja capaz de ensinar a criança a controlar seus impulsos e retardar a gratificação das recompensas de algum modo, independentemente se a educação dada pela família é mais tolerante ou mais restritiva. Os pais são as pessoas que se encontram, potencialmente, na melhor posição para proporcionar uma socialização adequada e pró-social aos seus filhos (RODRIGUES, 2011).

Contudo, é imprescindível que se compreenda que a família ainda é a primeira visão de mundo e sociedade que uma criança possui. Por isso é essencial que se compreenda como as práticas parentais se formam e como cada uma colabora e repercute no rendimento escolar das crianças. Afinal, a criança sempre será o reflexo da educação que recebe em casa, e esta educação compõem e repercute principalmente suas ações dentro do espaço escolar, e podem colaborar para possíveis problemas de aprendizagem.

\section{As Práticas Parentais: sua influência nos cenários educacionais familiar e escolar}

Diante de tantas mudanças ocorridas ao longo do tempo, a família acompanhou e continua a acompanhar todos os avanços e retrocessos que atingem a sociedade em geral. Com isso torna-se importante discutirmos a importância da família na construção social das crianças/filhos e como este ambiente familiar e também educacional, contribui para consolidação do indivíduo como ser social ativo de sua realidade. Como a família compõe a construção do sujeito em sua essência, é importante compreendermos que a escola surge como 
suporte e auxílio para que juntamente com a família possam desenvolverem nos filhos e alunos valores e condutas condizentes com os que a sociedade demanda.

Lacasa (2004) ao procurar fazer com que entendamos que tanto a família como a escola são dois hemisférios educacionais diferentes, mas, que deveriam lutar por um objetivo comum (a aprendizagem do filho/aluno), sanciona que "tanto o contexto familiar como o da escola são constituídos por pessoas que desempenham um determinado papel e que, além disso, utilizam instrumentos que cumprem determinadas funções" (p. 405). Estes instrumentos são estratégias utilizadas pelos pais, ou por quem exerce a responsabilidade pela criança (cuidadores), que denominamos de prática parental.

As práticas educativas parentais referem-se às estratégias utilizadas pelos pais para atingir objetivos específicos em diferentes domínios (acadêmico, social, afetivo) sob determinadas circunstâncias e contextos. Weber et al (2004) explicam que as práticas parentais estão ligadas a comportamentos e objetivos específicos relacionados a socialização do indivíduo, ou seja, a combinação de diversas e diferentes práticas parentais podem ocasionar um mesmo efeito em quem a recebe (o filho), variando do contexto no qual está inserido e das situações cotidianas específicas que irão gerar e criar uma determinada interação entre pais-filhos (LEME; BOLSONI-SILVA, 2010). Essas práticas são diferenciadas por alguns autores como repercussivas de estratégias que objetivam suprimir determinados comportamentos visto como inadequados (práticas negativas) ou capaz de incentivar e motivar a devidos comportamentos adequados e aceitáveis (práticas positivas).

As práticas parentais foram investigadas por Gomide (2006), através de um inventário (Inventário dos Estilos Parentais) que a autora desenvolveu para estudar a interação entre pais e filhos. A partir deste a autora caracterizou 7 (sete) práticas parentais que corroboram para criação dos estilos parentais e consequentemente para o desenvolvimento social ou antissocial dos filhos, e as dividiu em dois grupos, sendo um composto por práticas parentais educativas positivas que contribuem para o desenvolvimento "saudável" em requisito social, afetivo e cognitivo dos filhos, denominadas de: monitoria positiva e o comportamento moral; o outro grupo composto por práticas educativas consideradas negativas que se referem as práticas que podem colaboram para o desenvolvimento do comportamento antissocial das crianças, neste grupo estão as práticas: monitoria negativa, negligência, disciplina relaxada, punição inconsistente, e o abuso físico (GOMIDE, 2006; TEIXEIRA; OLIVEIRA; WOTTRICH, 2006; SAMPAIO; GOMIDE, 2007; BOLSONI-SILVA et al 2010).

Para Gomide (2006), a Monitoria Positiva é caraterizada como positiva pelo fato da afetividade fazer parte da construção familiar, são pais que demonstram afeto e muito carinho aos filhos, principalmente se passam por algum problema ou necessidade em que o apoio e o carinho dos pais são essenciais. $\mathrm{O}$ Comportamento Moral diz respeito a promoção de um ambiente familiar favorável para o desenvolvimento e transmissão de valores e virtudes, sendo estas como: senso de justiça, responsabilidade e trabalho, generosidade, honestidade e conhecimento do certo e do errado.

A Negligência é caracterizada por Gomide (2006), como sendo uma prática parental educativa negativa, pelo fato de fazer parte do "repertório" de pais que não estão atentos as necessidades dos filhos, tornando-se ausentes das responsabilidades parentais e afetivas, não procuram auxiliar os filhos nas tarefas do dia a dia, e tão pouco se importam com a estabilidade emocional de suas crianças. Monitoria Negativa (ou supervisão estressante) diz respeito a pais altamente controladores, que fazem uso de determinadas regras instruídas diversas e repetidas vezes, causando um excesso de fiscalização e aborrecimento sobre a vida dos filhos.

A Disciplina Relaxada condiz com o não comprimento ou relaxamento das regras impostas e estabelecidas pelos pais. Pais que fazem uso dessa prática considerada negativa, ameaçam alguma cobrança ou algum castigo, mas quando se veem confrontados e rebatidos pelos filhos, rapidamente voltam a trás e não realizam sua ação devido ao comportamento agressivo e rebelde dos filhos, ou seja, ele promete o castigo, mas não o efetiva, não o concretiza. Na Punição Inconsistente os pais agem de acordo com o humor que apresentam cotidianamente, ou seja, os pais cobram, punem, exigem de acordo com o seu humor expresso no dia específico. E por último, o Abuso Físico/Punição Corporal e também psicológica, que é visto pelas autoras (GOMIDE, 2006; SAMPAIO; GOMIDE, 2007) como a pior prática parental exercidas pelos pais. $\mathrm{O}$ abuso físico está relacionado à práticas punitivas negativas, ou seja, punições corporais, machucados, causando dores e marcas pelo corpo das crianças.

Contudo, podemos perceber que cada ação e prática parental remete a uma consequência, as diversas formas de educar espalhadas pelo país a fora, podem gerar inúmeras consequências e estão intimamente interligadas com o comportamento e desempenho de nossas crianças. Afinal a maneira que os pais irão guiar as crianças, mostrando as consequências de seus atos, como devem reagir e expressar seus sentimentos positivos e negativos, suas opiniões, os limites a serem obedecidos, até mesmo a forma de educar como uso da agressão e ameaça, consistirá nas chamadas práticas parentais (LEME; BOLSONI-SILVA, 2010).

\section{Método}

Este estudo possui um caráter exploratório e transversal e com um cariz eminentemente quantitativo. A abordagem exploratória neste estudo surge devido a temática em questão não ser algo comum no território brasileiro e principalmente na região Amazônica.

\section{Participantes}

Participaram da pesquisa 78 pais e/ou responsáveis (avós, tios, primos) dos alunos com idades entre 18 e 63 anos sendo a média de 34 anos. A amostra se constituiu por: $77.4 \%$ de Mães; $12.8 \%$ de Pais; $7.7 \%$ de Avós; 
$3.8 \%$ de Tios e $1.3 \%$ de outros responsáveis. As crianças tinham idades entre 6 e 12 anos, e frequentavam do $1^{\circ}$ ao $5^{\circ}$ ano, sendo $53.8 \%$ do sexo masculino.

A pesquisa foi realizada em uma Escola Pública Estadual do munícipio de Humaitá-AM. O grau de instrução dos cuidadores variou entre Ensino Fundamental incompleto ao Ensino Superior completo. A renda familiar majoritariamente prevaleceu a de menor renda, entre igual ou inferior a um salário mínimo (R\$ 888,00 - equivalente a 243 euros na cotação cambial de 14 de julho de 2017).

\section{Instrumentos}

Foi utilizada a Alabama Parenting Questionarie (APQ) - Versão Pais, para verificar as Práticas Parentais adotadas e os boletins escolares para verificar o rendimento acadêmico.

\section{Material a Procedimentos}

Os dados coletados foram analisados com recurso à estatística descritiva e da Análise de Variância Univariada-MANOVA.

\section{Resultados e Discussão}

A fim de entendermos quais as práticas parentais que caracterizava a amostra da pesquisa, foi identificado que as práticas parentais positivas possuem uma média maior de relevância do que as práticas parentais negativas. Desta forma, a prática parental mais presente encontra foi a prática do Comportamento Moral $(\mathrm{M}=$ 4.16); em segundo lugar encontramos a prática parental Monitoria Positiva $(M=4.04)$. Em sequência a amostra da pesquisa caracterizou as práticas Monitoria Negativa $(\mathrm{M} \quad=\quad 2.36) ; \quad$ Disciplina relaxada/inconsistente $(M=2.34)$; Negligência $(M=$ 2.29) e por último, a prática menos utilizada pela amostra foi a prática do Abuso Físico/Punição Corporal $(\mathrm{M}=2.25)$.

Diante dos objetivos propostos e resultados encontrados na nossa amostra pudemos observar que as práticas parentais 'Monitoria Positiva' e 'Comportamento Moral' possuem maior média, sendo consideradas entre as demais como as mais frequentemente utilizadas pelos pais desta pesquisa de acordo com suas respostas. Conforme a literatura vem apontando, o uso de práticas positivas como estas colabora para o melhor rendimento escolar dos filhos/alunos. Prata et al (2013) explicitam como as práticas positivas podem ajudar no melhor rendimento dos filhos afirmando que os pais devem se envolver nas atividades escolares dos filhos, auxiliando nas tarefas de casa e participando de atividades e reuniões promovidas pela escola. As crianças que tem o acompanhamento dos pais são mais incentivadas e acabam por ter o aproveitamento escolar esperado. As autoras destacam a importância principalmente do suporte parental como presença e preocupação com o cotidiano do aluno e atividades nas quais o filho esteja inserido. As práticas parentais educativas positivas repercutem para um bom rendimento escolar de maneira que, o envolvimento dos pais na vida e atividades dos filhos, através dos diálogos e de forma democrática corroboram para um melhor desempenho na escola e melhoram a autoestima e auto eficácia dos filhos.

Das MANOVAS realizadas entre as Práticas Parentais e o Rendimento Acadêmico dos alunos, tanto nas disciplinas isoladas como no coeficiente médio geral, encontramos influências significativas da prática parental positiva Comportamento Moral somente sobre o rendimento da disciplina Ensino Religioso ( $\boldsymbol{p}=$ .031). A interferência das práticas parentais nesta disciplina 'Comportamento Moral' talvez se explique pelo fato de a mesma estar ligada ao desenvolvimento moral das crianças, que também é construído em casa. Desta maneira, acaba por se tornar uma disciplina que condiz com os valores e condutas morais que estão sendo seguidos tanto na escola quando dentro de casa. Os valores aprendidos em casa estão condizendo com a mesma filosofia que a escola procura desenvolver. Não havendo controvérsias, as crianças entendem estes valores como sendo corretos e iguais, amenizando esta barreira que existe entre família e escola, possibilitando que compreendam e se saiam melhor na disciplina de Ensino Religioso por interligarem com os seus conhecimentos prévios e fazerem uso do que aprendem no seu cotidiano.

Com relação as práticas parentais negativas encontramos relações estatisticamente significativa entre a prática da Disciplina Relaxada/Inconsistente e as disciplinas de História $(p=.002)$ e Geografia ( $p=$ .001) e também entre a prática Monitoria negativa com a disciplina de Ciências $(p=.002)$. Sapienza, Aznar-Farias e Silvares (2007) postulam que os pais que fazem uso da prática Disciplina Relaxada/Inconsistente "demonstram pouca atenção e afeto, têm dificuldades para responder às iniciativas dos filhos e para o diálogo, estabelecem muitas regras independente de seu cumprimento, relaxam as regras já estabelecidas e punem fisicamente seus filhos" (p. 212), se tornando pais relaxados nas expectativas e interesse pela vida dos filhos. Não expressão clareza aos fillhos sobre os motivos da punição e muitas vezes permitem se levar por seu humor cotidiano, o que acaba gerando mais confusão ainda na cabeça da criança, que irá relacionar a maneira de punir com o humor do pai/mãe e não com as suas notas baixas ou comportamentos inadequados. Esse tipo de prática caracterizada como negativa, consequentemente tende a prejudicar o rendimento dos alunos como foi constatado em nossos dados, na medida que, a conversa e a interação pais e filhos se tornam distanciadas de uma convivência harmoniosa e motivadora para a melhoria de desempenho acadêmico.

Outra prática tida como repercussiva no desempenho escolar desta amostra foi a prática Monitoria Negativa em relação a disciplina Ciências. O uso desta prática está ligado ao estilo autoritário, pois a medida que os punem, também exigem muito de forma inconsistente, utilizando bastante o uso de cobranças e controle excessivo das ações e principalmente de um rendimento acadêmico "apresentável". Os pais exigem que seus filhos saiam de uma nota regular para ótima, e devido à alta exigência acabam apresentando abuso físico e 
psicológico para punir caso o filho não o atenda de maneira esperada, gerando filhos inseguros $\mathrm{e}$ amedrontados.

Diante deste estudo e das variáveis encontradas podemos compreender e diferenciar de que forma cada prática negativa e positiva podem causar determinadas consequências para o desenvolvimento moral, social, cognitivo e orgânico de cada criança. Percebemos a importância de se enfatizar o uso de práticas positivas e evitar o uso de práticas negativas que vêm sendo relacionadas ao baixo desempenho escolar, baixa autoestima, baixa auto eficácia, isolamento ou agressividade, entre outros comportamentos desajustados, ou seja, influenciando negativamente o desenvolvimento geral das crianças e jovens.

\section{Considerações Finais}

Diante do exposto podemos perceber a família como a principal e primeiro meio reprodutor de valores e construtora das relações sociais. Torna-se o local onde se efetua a maior parte das aprendizagens que construímos ao longo da vida, sobre as pessoas, o que somos e do que somos capazes de realizar. Consequentemente, a partir do primeiro contato com outro ambiente socializador e também reprodutor ideológico "a escola", que tem como função contribuir e auxiliar a família na construção de aprendizado e conhecimento científico essenciais, a aprendizagem acaba por ser tornar uma via de mão dupla, onde tudo que aprendemos, internalizamos e reproduzimos de volta para o meio.

Esta pesquisa permitiu percebermos que diversas são as maneiras de educar um filho, variando bastante do contexto social, cultural, e principalmente de cada família. Existem vários aspectos ambientais que influenciam na aprendizagem de uma criança, dentre eles podemos citar: o espaço escolar, o contexto familiar e as variáveis da própria criança, portanto, não podemos aqui citar ou identificar o grande propulsor do chamado fracasso escolar, afinal tudo a todo tempo se modifica e se cria através de diferentes valores, crenças, expectativas e consequências. Se as práticas parentais aqui discutidas, caracterizadas e observadas apresentaram suas contradições e outras expectativas, como podemos afirmar com convicção quais práticas e estilos parentais devem ser seguidos pelos pais ou cuidadores?

Não podemos negar que o suporte parental construído e edificado na infância trará grandes contribuições para o desenvolvimento moral de todo o ser humano. Os pais como bons progenitores, que demonstram envolvimento na vida dos filhos tanto emocional como escolar, disponibilizando tempo e recursos para o melhor desenvolvimento do filho e colaborando para um clima emocional familiar estável e harmonioso, tende a promover um melhor desempenho psicológico, afetivo e cognitivo em suas crianças. Afinal, as crianças esperam antes de qualquer coisa, receber amor, apoio, compreensão, consolo e um bom humor dos seus pais. Diante disto, observamos as práticas parentais positivas como trilhos a ser seguidos para a construção de indivíduos seguros e autoconfiantes.

\section{Referências}

Bolsoni-Silva, Alessandra Turini et al. (2010). Práticas parentais e repertório infantil: caracterização da demanda por atendimento e predição de abandono. Aletheia, n. 32, p.121-133.

Gomide, P. I. C.(2006). Inventário de Estilos Parentais. Modelo teórico: manual de aplicação, apuração e interpretação. Petrópolis: Vozes.

Lasaca, Pilar. (2004). Ambiente familiar e educação escolar: a interserção de dois cenários educacionais. En: Cesár Coll, Alvaro Marchesi e Jesús Palacios e cols (org.). Desenvolvimento psicológico e educação. 2. ed. Porto Alegre: Artmed.

Leme, Vanessa Barbosa Romera; Bolsoni-Silva, Alessandra Turini (2010). Habilidades sociais parentais e comportamentos de pré-escolares. Estudos de Psicologia, v. 15, n. 2, p. 161-173, 2010. Disponível em: www.scielo.br/epsic. Acessado em: 18 dez. 2016

Nery D. Juliana (2012). Rousseau e o conceito de infância: uma leitura a partir da obra Emilio ou Da Educação.Trabalho de Conclusão de Curso de Graduação em Pedagogia, Universidade Estadual de Maringá, Maringá, Brasil. http://www.dfe.uem.br/TCC/Trabalhos_2012/JULIA NA_DE_NERY.PDF

Prata, Ana et al. O impacto dos estilos educativos parentais e do desenvolvimento vocacional no rendimento escolar de adolescentes. Análise Psicológica, v. 3, n. 31, p. 235-243, 2013. http://dx.doi.org/10.14417/S0870-8231201300030002

Rozek, Marlene; Serra, Rodrigo Giacobo (2015). Dificuldades de aprendizagem e problemas emocionais: reflexões sobre a necessidade de uma proposta de formação docente. Educação Por Escrito, Porto Alegre, v.6, n. 1, p.167-184.

Rodrigues, Yara (2011). Autoridade familiar, autoconceito e valores: Um estudo com alunos do $7^{\circ}$, $9^{\circ}$ e $11^{\circ}$ anos de escolaridade. Dissertação de Mestrado em Educação, Universidade de Lisboa, Lisboa, Portugal. http://repositorio.ul.pt/bitstream/10451/4619/1/ulfpie0 39590_tm.pdf

Sampaio, Izabela Tissot Antunes; Gomide, Paula Inez Cunha (2006). Inventário de estilos parentais (IEP) Gomide (2006) Percurso de padronização e normatização. Psicol. Argum., Curitiba, v. 25, n. 48 p. 15-26, 2007.

Sapienza, Graziela; Aznar-Farias, Maria; Silvares, Edwiges Ferreira de Mattos (2017). Competência Social e Práticas Educativas Parentais em Adolescentes com Alto e Baixo Rendimento Acadêmico. Psicologia: Reflexão e Crítica, v. 22, n. 2, p. 208-213, 2009. Disponível em: www.scielo.br/prc. Acessado em: 09 jan. 2017.

Silva, Cláudia Maria Rinhel (2009). Família, adolescência e os estilos parentais. Dissertação de Mestrado em Letras da Universidade Estadual 
Paulista, Assis, Brasil. $<$ http://hdl.handle.net/11449/97566>.

Teixeira, M. Na. P., Oliveira, A. M., Wottrich S. H. (2006). Escalas de Práticas Parentais (EPP): Avaliando Dimensões de Práticas Parentais em Relação a Adolescentes. Psicologia: Reflexão e Crítica, v. 19, n. 3, p. 433-441.

Weber, Lidia Natalia Dobrianskyj et al. Identificação de Estilos Parentais: O Ponto de Vista dos Pais e dos Filhos. Psicologia: Reflexão e Crítica, v. 17, n. 3, p.323-331, 2004.

\section{Agradecimientos}

Esse estudo fez parte da pesquisa realizada como exigência para a Conclusão do curso de Graduação em Pedagogia, realizado pela primeira autora sob orientação da segunda autora. 